\title{
THE CONTINUING PROFESSIONAL DEVELOPMENT OF TEACHERS FOR SCHOOLS' INOVATIVE TEACHING METHODS
}

\author{
M. Velikova* \\ Department for Information and In-Service Training of Teachers, \\ Sofia University “St. Kliment Ohridski”, Sofia, Bulgaria
}

\begin{abstract}
The professional development of teachers is necessary not only to meets the standards of job realization, but also to improve their activities in response to changes in pedagogical science and practice. This report presents the results of the research project "Current status and trends for the application of innovative methods in school's activities" durring the National Program "Young Scientists and Postdoctoral Students" in 2019. The aim of the study is to indicate the teachers' attitude to the application of innovative teaching methods in their practice in school.
\end{abstract}

Key words: professional development of teachers, innovative teaching methods

\section{INTRODUCTION}

The development of modern societies requires the application of new forms of innovative education in order to build and form a generation of creative people. The ways and forms of organization of the whole school life are necessary to stimulate their development in the maximum extent. The innovations in teaching provide an opportunity to 'break the framework' of traditional teaching and learning and to diversify the didactic tools. This provides new opportunities to increase the effective and successful training. The ongoing changes in the development of education today require school organizations' activity for "continuing professional development" of their staff (teachers, management and administration). This includes 'all activities teachers are engaged with throughout their careers and which are designed to renew their work'. (1)

The main condition for maintaining a high quality is the implementation of permanent qualification, which aims to refresh

\footnotetext{
*Correspondence to: $M$. Velikova, Sofia University "St. Kliment Ohridski”, Department for Information and In-Service Training of Teachers, Sofia, Bulgaria, e-mail: mi.velikova@gmail.com, msvelikova@uni-sofia.bg
}

knowledge, get acquainted with current issues, preparation for new curriculum and more. The growing dynamics in the development of scientific knowledge and the changing conditions of the external environment require constant enrichment and renewal of the professional training of the teachers. (2) Over the past decade, a rich variety of training programs for the qualification of pedagogical specialists, divided into thematic areas and academic discipline has been created. The focus of these programs is on various current topics to help improve the knowledge and skills of Bulgarian pedagogues: formation and development of skills for building innovative, creative, positive and supportive educational environment; work in a multicultural environment; implementation and use of information computer technologies in the educational process; prevention of dropping out of school; prevention and reduction of bullying and violence at school; effective techniques for communication and work with parents; innovative forms and methods for teaching and assessment; increasing the methodological, administrative and managerial competence of the pedagogical specialists.

The continuing professional development of teachers includes also other activities related to their training: using of professional literature, 
attending courses, workshops, seminars and conferences, coach training, peer supervision, team teaching, dissemination of good practices, giving a feedback, searching for Internet resources, discussing articles, books and more. The listed examples of qualification programs and professional development activities (as well as others) should lead to positive results in the work of the teachers. C. Dey distinguishes two directions in the continuing professional development of teachers: "managed professionalism" (institutionally managed) and "democratic professionalism" (personally managed). Unlike the first type, in which the continuing professional development is directed by the respective institutions (through policies, normative documents, requirements, etc.), in the second type, the teachers direct it according to their own preferences. This way, they are flexible, proactive, with a creative charge, which transforms them into an innovative factor.

\section{MATERIALS AND METHODS}

This report presents the results of research project 'Current status and trends for the application of innovative teaching methods in school's activities' in connection with the implementation of research activities under the National Program 'Young Scientists and Postdoctoral Students' in 2019. The aim of the study is to indicate the teachers' attitude to the application of innovative teaching methods in their practice in the school. The participants in the study were teachers, who lead curricular and extracurricular activities in schools in small, medium and large cities in Bulgaria. The questionnaire created for the purpose of the research consisted questions about: the practice of using innovative methods; motivation for their application in the learning process; assessment of the possibilities of innovative methods; degree of awareness of innovative teaching methods; demographic characteristics.

The study involved 562 active teachers $(87 \%$ women and $13 \%$ men), avarage age 46 years (between 22 to 68 years of age), from small, medium and large cities in all regions of Bulgaria. Almost all (97\%) work in public, municipal schools. They teach different stages of education and different academic discipline. Most teachers work in Primary school (I - VII grade), Professional High school and Secondary school (I - XII grade) (Table 1). The number of surveyed teachers in relation to the region in which they work is evenly distributed: $32 \%$ in large, $30 \%$ in medium and $29 \%$ in small cities. Only $8 \%$ of the responders work in the schools, located in the capital. It means that the results will present an up-todate picture with an emphasis on general education schools outside Sofia, the capital of Bulgaria.

Table 1. School category acording to education type

\begin{tabular}{r|l}
$45 \%$ & Middle school (year I-VII included) \\
\hline $20 \%$ & Professional gymnasium \\
\hline $18 \%$ & High School (year I-XII included) \\
\hline $8 \%$ & Primary School \\
\hline $3 \%$ & Specialised Gymnasium \\
\hline $2 \%$ & Gymnasium (year VIII-XII included) \\
\hline $1 \%$ & United school (year I-X included) \\
\hline $0.6 \%$ & Private school (for extracurricular activities) \\
\hline
\end{tabular}

The questions aim to outline the current trends in the application of non-traditional techniques in the modern schools. Almost all surveyed teachers $(97 \%)$ say that they apply innovative methods in their practice. Of these teachers, 92\% train students in curricular activities, $58 \%$ are engaged in extracurricular activities, and $18 \%$ practice in extracurricular activities in 
other educational institutions. The great interest in the non-traditional way of teaching is obvious among the teachers in Bulgaria. The importance of this result is reinforced by the fact that only $22 \%$ of the surveyed teachers work in schools with the status of "innovative school", which are characterized by the introduction of various elements of innovation. As the focus of this study is on the continuing professional development of teachers, therefore of the innovative teaching methods will be presented only those that teachers apply in their practice. Teachers' answers outline a diverse palette of teaching methods that they apply in their practice to put 'students in the role of discoverers when the teacher is only a helper in the process.' The most popular of them are the game approaches, with roleplaying games most often mentioned. Next are the discussion methods (discussion, brainstorming, conversation, debate, 'Aquarium', interview, mind maps, etc.). The use of digital and new technologies is also among the most familiar to teachers, and they pay special attention to video lessons. Of course, in each of the listed methods there is a group work, which ranks next among the teachers' answers. Project-based activities, situational methods and interactive learning are the next most popular among teachers. They also share interdisciplinary studies, a flipped classroom, experiential learning, the use of presentations, outsourced training, laboratories, workshops and project-based learning with parents. From the answers of almost all surveyed teachers it can be noticed that their familiar methods are already existing, but probably rediscovered and applied by them today and they are often perceived as innovative. This is confirmed by the teacher's opinion: 'Some of the methods, which I use, are not considering innovative practices. They are already a tradition, which does not make them worse.'

The process from identifying innovations to their implementation in practice is long and sometimes complex. People are at the heart of changes, and the learning process will change and evolve when those involved do. Therefore, the interest in the present study is the sources and ways to acquire knowledge and skills on innovative methods from the teachers. The results in Table 2 show that they have the most confidence in continuing education trainings and courses, online resources and their colleagues. They also enrich their knowledge and improve their practical skills during scientific conferences and seminars.

Table 2. Sources of information about innovative teaching methods

\begin{tabular}{l|l}
$81 \%$ & trainings / courses \\
\hline $71.4 \%$ & internet sources \\
\hline $52.7 \%$ & discussion with colleagues \\
\hline $40.4 \%$ & participation in scientific conferences, seminars \\
\hline $28.6 \%$ & specialized literature \\
\hline $0.4 \%$ & I am not interested in innovative methods
\end{tabular}

These results show the potential of organized trainings for continuing professional development of teachers and outline the need for their continued implementation. As they are the teachers' main source for acquiring knowledge and skills, they must meet the current changes and needs of the educational process. Among the trainings for professional development of teachers are those related to innovative teaching methods, as the frequency of attendance can be seen in Figure 1. The teachers' motivators for participation in qualification forms of training for innovative teaching methods are personal initiative (for $60 \%$ of teachers), requirement and recommendation from the school principal (for $46 \%$ of teachers), due to the requirement for participation and collection of credits (for 34\% of teachers), on the recommendation of colleagues (for $16 \%$ of teachers). 


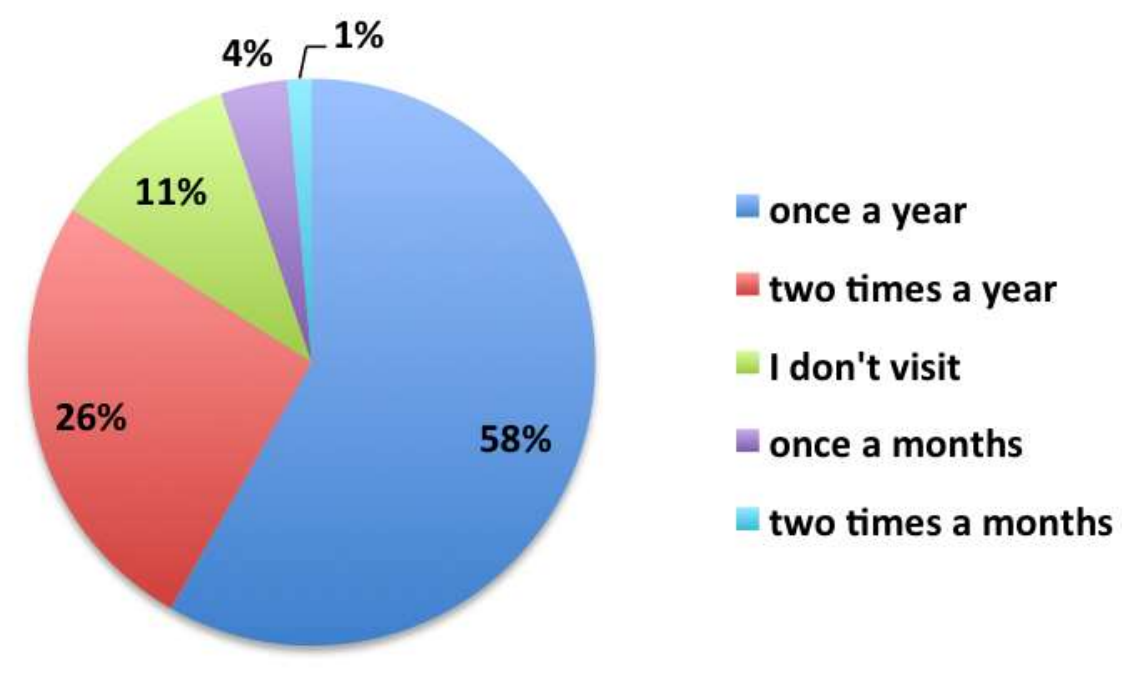

Figure 1. Do you attend or attended trainings related to innovative teaching methods?

The results show that the continuing professional development of the surveyed teachers is stimulated more by the respective institutions than motivated by their own preferences. However, there is a relatively balanced relationship between "managed professionalism" (institutionally managed) and "democratic professionalism" (personally managed) for continuing professional development. The surveyed teachers who do not attend trainings for innovative teaching methods (20\%) share that courses for innovative methods are not offered in their location, they don't have enough time, don't know or don't have information whether there are such trainings in their locality, they don't have the financial means or there are no courses for innovative methods that they like. $88 \%$ of the surveyed teachers confirmed the positive impact of the training on their pedagogical work and shared what they have learned to their colleagues as well. A small part of them $(7 \%)$ are of the opinion that their colleagues are not interested in such teaching methods.

\section{CONCLUSION}

The basis of the requirement for constructive change and development of the Bulgarian school is the belief that the preparation and stimulation of teachers to apply and create pedagogical innovations will increase the quality and satisfaction of all participants in the educational process.

\section{REFERENCES}

1. Day, C., J. Sachs. (2014). International Handbook of the Continuing Professional Development in Education, 3.

2. Penkova, R.) Programs for raising the qualification of the pedagogical specialists. Continuing education 14/2019. Available on 01.08.2020 